\title{
Capital Structure and Firm Performance in the Financial Sector: Evidence from Australia
}

\author{
Vedran Skopljak \\ School of Economics and Finance, La Trobe University \\ Kingsbury Drive, Bundoora, Vic 3086, Australia \\ Tel: 61-3-9479-1111Ｅ-mail: vedran.skopljak@latrobe.edu.au \\ Robin H. Luo (Corresponding author) \\ Department of Finance, Wuhan University \\ Luojia Hill, Wuhan 430072, China
}

Tel: 86-27-6875-2740Ｅ-mail: robin.h.luo@gmail.com

Received: January 29, 2012 Accepted: March 1, $2012 \quad$ Published: June 1, 2012

doi:10.5296/ajfa.v4i1.1319 URL: http://dx.doi.org/10.5296/ajfa.v4i1.1319

\begin{abstract}
How does capital structure affect firm performance of Authorised Deposit-taking Institutions (ADIs) using explicitly Australian data? This paper investigates the relationship between capital structure and firm performance of Australian ADIs. Our findings show a significant and robust quadratic relationship between capital structure and firm performance of Australian ADIs. At relatively low levels of leverage an increase in debt leads to increased profit efficiency hence superior bank performance, at relatively high levels of leverage increased debt leads to decreased profit efficiency as well as bank performance. This can most likely be attributed to financial distress outweighing any gains made from managerial performance improving.
\end{abstract}

Keywords: Profit efficiency; Capital structure; Agency cost theory, Financial sector 


\section{Introduction}

Capital structure and its effect on firm performance has long been a topic of discussion, with no shortage of papers on the issue (e.g. Modigliani and Miller, 1958; Myers, 1977; Jensen and Meckling, 1976; Harris and Raviv, 1991 and Margiratis and Pslilaki, 2007). However, these papers are very general in their conclusions and their reach to the financial sector is relatively limited. The reason being that the financial sector has its own unique set of regulations, and is generally highly leveraged; nevertheless, the underlying imperatives still apply to the financial sector just as they do for firms across other disciplines.

This paper mainly investigates the relationship between capital structure and firm performance of Australian Authorised Deposit-taking Institutions (ADIs). Based on agency cost theory (Jensen and Meckling, 1976), it suggests that debt is used as a motivating factor for managerial staff. Agency theory states that separation of top end management and ownership has a negative effect on firm performance; there is no incentive for management to perform at maximum capacity. Debt is enrolled as an instrument to heighten work ethic and performance of management; however an increase in the proportion of debt causes the firm to experience higher financial distress (Harris and Raviv, 1991). The main hypothesis to be explored in this paper contributes to academic research in this field in two major ways. First, research papers in the field of capital structure have not often concentrated on the effect of capital structure on profit efficiency, especially linking the two in the financial sector. The general method has been to try linking capital structure with firm performance using common financial ratios. One notable research paper by Berger and Bonaccorsi di Patti (2006) stands out as offering a significant and comprehensive empirical contribution to the link of capital structure and profit efficiency in the financial sector. The financial sector is fundamentally different from any other sector of the market in terms of its high leverage and regulation, therefore the results obtained from papers using data across multiple sectors in the market cannot be directly carried over to the financial sector with a high degree of confidence. Second, papers on the relationship of capital structure and Australian Financial sector "firm" performance are very scarce. It is clear that Australia has its own set of unique market conditions and regulations, which highlights the importance of extending Berger and Bonaccorsi di Patti's (2006) paper specifically for Australian data.

Australia intrinsically has a limited financial market with relatively few financial firms in operation therefore it is to be expected that our sample size is relatively small. Our final dataset consists of 15 Australian ADIs and their data was collected over years 2005-2007 of operation. Part of the reason the relationship between capital structure and firm performance has been known to show contradictory correlation empirically is the fact that a proxy for firm performance has been so difficult to obtain; some form of stock return or a common financial statement ratio has usually been used in the past. Although it is an unfortunate fact that these can be manipulated with relative ease, providing a clouded measurement of firm and managerial performance. This paper uses a modified version of Berger and Mester's (1997) measure of firm performance-profit efficiency. The measure is a proxy for the productive efficiency of management, linking agency cost with firm performance, which makes it an accurate and practical tool. Along with the profit efficiency measure this paper uses a common financial ratio, Return on equity (ROE), in order to provide robustness to the results.

Reverse causality has also been identified by previous studies (Berger and Bonacorrsi di Patti 2006) as a possible cause of curious results. It has been argued that it is in fact firm performance which affects capital structure, rather than the other way around. This paper will 
therefore test for reverse causality by performing Granger-causality tests on the relationships of capital structure and firm performance.

The findings of this paper confirm no significant linear relationship between capital structure and firm performance, however importantly the relationship is significant and robust once a quadratic capital structure term is added. This leads to the conclusion that increased debt improves bank performance at relatively low levels of leverage while at relatively high levels of leverage the effect of financial distress exceeds the beneficial effects of debt on managerial performance and therefore leads to decreased bank performance. Several robustness checks are performed and discussed which also yield favourable results.

The paper is structured as follows. Section 2 reviews major prior literature on the relationship of capital structure and firm performance as well as specific studies of the financial sector. Section 3 presents the methodology employed in our study. Section 4 addresses the data and explanatory variables in the study. Section 5 reports the empirical results including the estimation of profit efficiency and the effect of explanatory variables on profit efficiency. Section 6 offers a conclusion of the paper.

\section{Literature Review}

\subsection{Agency Cost Theory, Capital Structure and Firm Performance}

Agency cost theory is a logical concept which states that the separation of goals for management and ownership in a firm may lead to negative consequences in its performance. The fundamental thought process behind the theory is that when ownership and management are separate entities they do not share a common goal. (Jensen and Meckling, 1976) Since it is management who is in control of key decision-making, this separation is detrimental to firm performance. Two key assumptions are made in regards to the management and owners of firms for this theory to hold.

The human assumption (Eisenhardt, 1989) argues that management suffers from human imperfections, which manifest themselves in the form of self-interest. Despite managements major role being that of maximizing firm performance, it is driven by a bounded rationality whereby the optimal choices for the firm may be foregone in favour of decisions that lead to personal gain. The organizational assumption (Eisenhardt, 1989) states a firm may have many owners whose measure of performance may differ from one another. This leads to partial goal conflict among participants.

The key behind optimizing efficiency and minimizing agency cost is the unification of managerial and ownership goals (Jensen and Meckling, 1976). One way of unifying these goals is to instil responsibility into management through partial ownership (Fama and Jensen, 1983). Shares are issued to management as part of their contractual wage agreement. This is a relatively simple, yet effective way of creating an incentive based wage to management, who are therefore forced to work harder to increase firm performance as well as their wage.

More closely related to this paper is the theory behind minimizing agency cost through increasing debt levels. Though the idea of debt levels being tiedto agency cost may sound trivial at first, the theory is quite difficult to refute. According to Harris and Raviv (1991), debt can act as a monitoring and incentive device, since there is a positive correlation between higher debt levels and higher financial distress. A company is more likely to face bankruptcy if it is experiencing high financial distress: this fact drives management to improve firm performance, as it does not want to suffer job loss and/or a bad reputation as a 
consequence of bankruptcy (Opler and Titman, 1994; Grossman and Hart, 1982).

For the empirical studies, Margiratis and Psillaki (2007) test for profit efficiency and the role capital structure plays in its determination. They define profit efficiency as the difference between maximum potential output and actual output while keeping input constant. These inefficiencies are considered to be direct outcomes of agency cost. Furthermore, reverse causality is tested for by regressing firm performance as measured by profit efficiency against the capital structure of firms. This investigates the validity of the efficiency-risk hypothesis and the franchise value hypothesis. A very similar definition of profit efficiency to that of Berger and Bonaccorsi di Patti (2006) is adopted in Margiratis and Psillaki's (2007) paper. A comprehensive 12,240 New Zealand firms from the 2004 New Zealand Annual Enterprise Survey make up the data-set. These are primarily constituted by Small and Medium Enterprises, and according to the Ministry of Economic Development in New Zealand are defined as employing less than 19 workers. Their findings match expectations gathered from agency cost theory, pecking order theory, and to a lesser extent, static theory. Using the entire range of data they conclude that debt levels have a significant, positive affect on profit efficiency. In other words, the observations show that an increase in proportions of debt level lead to an increase in profit efficiency (which is used as a proxy for firm and managerial performance).

Furthermore, the data is then tested for reverse causality; this incorporates testing for the efficiency-risk hypothesis, as well as the franchise-value hypothesis. The former hypothesis states that more efficient firms choose higher debt to equity ratios, as higher efficiency reduces the cost of bankruptcy risk and financial distress. The latter states that more efficient firms may choose lower debt to equity ratios in order to protect economic rents derived from higher efficiency from the possibility of liquidation. Quantile regression is used to test for reverse causality and therefore the effect of firm efficiency on debt proportions. The findings show validity of both hypotheses, though at different spectrums of the data. At the low to mid range of the leverage distribution, more efficient firms select higher debt level showing evidence for the efficiency-risk hypothesis. At the high end of the leverage distribution range, evidence for the franchise-value hypothesis is shown; higher efficiency firms choose relatively lower debt ratios.

Opler and Titman (1994) specifically study the effects of financial distress among high leveraged firms in relation to relatively low debt firms during industry downturns. The firm performance acts as proxy by operating profit as well as relative market share. It is found that, as predicted in the franchise-value hypothesis, highly leveraged firms do suffer more than their low debt counterparts in an economic downturn.

Cambello (2003) studies the impact of capital structure on firm performance of product markets in booms and recessions. He found that firms with high debt are affected most (negatively) by recession when there are competitors with relatively lower debt financing in direct contest. No such relationship was witnessed for firms operating in high debt industries. Since the financial sector is a highly leveraged industry this paper will go on to further test Cambello's findings.

Agrawal and Knoeber (1996) examine seven control mechanisms which are commonly used to manage agency cost of firms. Among them is a control variable for debt, and the paper's findings contradict that of agency cost theory; increased debt proportions have a significantly negative affect on firm performance when the ordinary least squares regression (OLS) was run. These results may be fogged, however, by statistical limitations such as multicollinearity 
etc., Such statistical flaws can cause individual variables to take on inaccurate or skewed values. When the two-stage least squares (2SLS) model is run using the same data-set, debt is insignificant but shows a positive sign in regard to firm performance.

\subsection{Capital Structure and Firm Performance in Financial Sectors}

As stated earlier, it is important to distinguish the financial sector from the rest of the market when attempting to find a relationship between capital structure and firm performance in the financial sector. Banks in general operate under a totally unique and rigorous set of regulations which only apply to that sector, making it impossible to explain the relationship of both the banking market and the rest of the market using only a single model or indeed a single dataset (Barth et al., 2004). For example, Australian ADIs do not only have to abide by the general rules enforced by law on all firms, but they also have an additional set of regulations which subject banks to requirements, guidelines and restrictions.

Barth et al. (2001) undertake an ambitious study in an attempt to compare 107 countries and their banking systems. They test for regulatory power, supervision and other factors which are deemed important in comparing banking systems. Australia is almost always on the cautious side of the scale in all disciplines. Australia has a high degree of supervision, with 2 major bodies over viewing the banks; The Australian Prudential Regulation Authority (APRA), whose lone task is to protect depositors through limiting and supervising risk levels taken on by ADIs, and the Australian Securities and Investment Commission (ASIC), who is responsible for information being made transparent and available to the market as soon as the information is presented to the directors of companies to carry out their acts in honesty, ASIC also investigates the level of efficiency and fairness in the market.

In addition to these Australian regulatory bodies, the financial sector is subject to the Basel II Accord, first published in 2004, which is an international document outlining the importance of strict risk and capital management requirements, with major emphasis being placed on minimum capital requirements for individual banks. Furthermore, banks are fundamentally highly leveraged relative to the rest of the sectors in the economy, making banks a distinctive test subject for the hypotheses this paper intends to answer.

Studies which empirically test for "real world" accuracy of capital structure theory are not in shortage. Empirical research on this topic from an Australian viewpoint, especially regarding the financial sector, is quite scarce, however. The focus in this paper will have a particular emphasis on a comprehensive and widely regarded US study conducted by Berger and Bonaccorsi di Patti (2006), and will then be applied to the Australian financial sector. Studies which came before it often used regular accounting and financial measures as proxies of firm performance (such as ROE, returns on stock market, profit etc.), and although these are useful in portraying the performance of a firm, they offer no distinction between management that is excelling and management that is underperforming. Berger and Bonaccorsi di Patti (2006) argue that a more appropriate measure to test firm performance is profit efficiency; it accounts for managerial performance as well as the extent of agency cost suffered by the firm.

Berger and Mester (1997) initially introduce two measures of profit efficiency, the first of which is; 


$$
S P E F F^{t}=\frac{\hat{\pi}^{i}}{\hat{\pi}^{\max }}=\frac{\left\{\exp \left[\hat{f}_{\pi}\left(W^{t}, p^{t}, z^{t}, v^{t}\right)\right] \times \exp \left[\ln \hat{u}_{\pi}^{t}\right]\right\}-\theta}{\left\{\exp \left[\hat{f}_{\pi}^{t}\left(W^{t}, p^{t}, z^{t}, V^{\prime}\right)\right] \times \exp \left[\ln \hat{u}_{\pi}^{\max }\right]\right\}-\theta}
$$

which is based on the firm profit function:

$$
\ln (\pi+\theta)=f_{\pi}(w, p, z, v)+\ln u_{\pi}+\ln \varepsilon_{\pi}
$$

where $\pi$ is the net variable profit of a firm (revenue - expenses including interest earned and paid); $\theta$ is a constant added to every firm so that the natural log is a positive value; $w$ and $p$ are vectors of prices for inputs outputs respectively; $z$ is the net quantity of fixed output - inputs and $v$ is a variable taking into any other factors affecting profit. The $\ln u_{\pi}$ variable represents inefficiencies that reduce overall profit, firms with the highest estimated $\ln u_{\pi}$ value are considered to be engaging in the most efficient business practice, and are denoted as $\ln \hat{u}_{\pi}^{\max }$. This bank then becomes the benchmark to which Berger and Bonaccorsi di Patti base profit efficiency on. A bank with an SPEFF of .7 earns $70 \%$ of its maximum potential profits.

The second specification to measure profit efficiency as described by Berger and Mester (1997);

$$
A P E F F^{\prime}=\frac{\alpha \hat{\pi}^{\prime}}{\alpha \hat{\pi}^{\max }}=\frac{\left\{\exp \left[\hat{f}_{\alpha \sigma \pi}\left(w^{\prime}, y^{\prime}, z^{\prime}, v^{\prime}\right)\right] \times \exp \left[\ln \hat{u}_{\alpha \pi}^{t}\right]\right\}-\theta}{\left\{\exp \left[\hat{f}_{\alpha \pi}^{l}\left(w^{\prime}, y^{\prime}, z^{\prime}, v^{\prime}\right)\right] \times \exp \left[\ln \hat{u}_{\alpha \pi}^{\max }\right]\right\}-\theta}
$$

The alternative profit efficiency function is derived from the alternative profit function;

$$
\ln (\pi+\theta)=f_{\alpha \pi}(w, y, z, v)+\ln u_{\alpha \pi}+\ln \varepsilon_{\alpha \pi}
$$

Although the alternative profit efficiency function is calculated in a similar way to the standard one, there is a distinct difference between the two. This difference is the replacement of output price with output quantity as an exogenous variable, hence the price (p) variable is replaced by the output quantity variable $(y)$ in the alternative function.

The data was collected of 7,548 banks; a sub-sample, "the ownership sample", was created, for which detailed information on the insider holdings, block holdings of $5 \%$ or more (by insiders or outsiders), and institutional holdings of the bank, or its top-tier holding company, is available. This data was then gathered over the time period of 1990-1995, using a cross sectional model describing the relationship between average efficiency (EFFi) overtime and average capital ratio over time (ECAPi), while keeping averages for most control variables (except some ownership variables). Since we are using very similar variables both the exogenous and endogenous variables will be described in detail in the next chapter.

The paper uses a two-stage least squares method (2SLS) model, it is most frequently used when there is a possibility of reverse causality being present, this is due to the underlying assumption of 2SLS being that there is no correlation between the primary model and the model testing for reverse causality. There are arguments for capital structure being affected by firm performance rather than it being the other way around hence for the purpose of checking for reverse causality, the efficiency risk and franchise-value hypothesis are tested by specifying the equity capital ratio as a function of the firm's profit efficiency. 
The findings of the main hypothesis tested by Berger and Bonaccorsi di Patti (2006), that being the agency cost hypothesis, is found to be significant, as an increase of debt proportions of $1 \%$ leads to an increase in efficiency of about $16 \%$ at the sample mean; showing also that lower equity capital ratios are associated with higher profit efficiency over the whole spectrum of data. In the case of testing for reverse causality, a similar conclusion is found to that of Margiratis and Psillaki (2007). Neither the efficiency-risk nor the franchise-value hypotheses empirically dominate the other over the entire range of data.

Maudos et al. (2000) undertake a study of both cost and profit efficiencies across countries. The paper tries to identify relationships between cost and profit efficiencies along with testing for the prevalent theories in the field of efficiency based performance. Their dataset includes a total of 832 firms across 10 European countries and the regressions are run using several panel data frontier approaches, these are the distribution free approach (DFA), the fixed effect model (FEM) as well as the random effects model (REM).

The findings show relatively higher inefficiencies in profits rather than costs, this implies that there are inefficiency issues on the revenue side of banking which may need to be analysed. A low positive correlation was found between cost and profit inefficiencies which go against Berger and Mester's (1997) findings which show no correlation of cost inefficiencies and profit inefficiencies. Further findings of Maudos et al. (2000) include that medium sized banks (assets $<\$ 10,000,000,000$ ) are most efficient on both the cost and profit side of things, as stated by agency theory banks with a high loans/assets ratio as well as high risk are relatively more efficient.

\section{Methodology}

Efficiency measures have a considerable place in academic circles, not only in the field of economics and finance but in every imaginable discipline. Since finding a way of determining efficiency can be quite challenging, attention has to be paid to the specification of the efficiency for results to be desirable and correct.

In light of these factors, this paper attempts to format a simple and easily accessible profit efficiency equation which yields correct and robust profit efficiency figures. Berger and Mester (1997) developed relatively complex albeit comprehensive efficiency evaluations as mentioned in section 2.3. The problem with employing the same exact specification is that Berger and Mester (1997) had a dataset of 5949 banks, hence their efficiency evaluation method is appropriate to use in the case where a sample size as large as that is available. In the case of our study which considers Australia exclusively, sample size becomes quite an issue. Therefore a primary objective was to create a simplified profit efficiency measure based on those of Berger and Mester (1997) as well as Muados et al. (2000).

Equation 5 shows the specification which was developed in order to maintain consistency with efficiency measures in past papers while being simple enough to be used for a sample of similar size to ours:

$$
\begin{aligned}
& \text { PEFF }=\alpha+\ln \left(X 1_{i}\right)+\ln \left(X 2_{i}\right)+\ln \left(C 1_{i}\right)+\ln \left(C 2_{i}\right)+\ln \left(C 3_{i}\right)+\ln \left(X 1_{i} / C 1_{i}\right) \\
& +\ln \left(X 1_{i} / C 2_{i}\right)+\ln \left(X 1_{i} / C 3_{i}\right)+\ln \left(X 2_{i} / C 1_{i}\right)+\ln \left(X 2_{i} / C 2_{i}\right)+\ln \left(X 2_{i} / C 3_{i}\right) \\
& +\ln \left(P_{i} / A_{i}\right)+\ln \left(P_{i}\right) / \ln \left(E_{i}\right)
\end{aligned}
$$

where PEFF is the profit efficiency, $X_{i}$ is the respective output of the respective bank, $C_{i}$ is the respective input of the respective bank, $P_{i}$ is the respective profit, $A_{i}$ is the 
respective asset and $E_{i}$ is the respective equity.

The alpha term $(\alpha)$ represents a constant term added on to all the figures in order to standardize the inevitable outlying negative values to positive ones (in order for their respective efficiency values to be positive). This is common practice and is exercised both in Berger and Mester (1997) as well as in Muados et al. (2000). Naturally adding the alpha term creates some figures of very low profit efficiency and although these figures may seem inaccurate or extreme, the fact is an extremely low profit efficiency figure reflects the banks gross inability to convert inputs into outputs efficiently relatively to the most efficient bank.

The ratio of outputs against inputs $(\mathrm{Xi} / \mathrm{Ci})$ measures the ability for each banks potential to convert each input into each output, therefore banks with larger figures for $(\mathrm{Xi} / \mathrm{Ci})$ suggests they are more efficient in converting costs into revenue. The control variables of $\mathrm{Pi}, \mathrm{Ai}$ and $\mathrm{Ei}$ have the responsibility of allowing the model to deflate the models efficiency which is based on purely these factors.

Having such control variables enables the model to process profit efficiency correctly rather than skewing figures of efficiency for banks based on their outright profits, assets or indeed equity. The profit efficiency measures the relative performance of management to that of the "best performing bank". An efficiency value of 1 would mean the bank is the "best performing bank" therefore this is the upper limit of possible efficiency values for our dataset. The differences of observed values relative to "the best performing bank" provide us with the percentage amount of inefficiency in the corresponding firm. Intuitively values closer to 1 describe banks with relatively low inefficiencies while values closer to 0 show higher inefficiencies. The lower limit of profit efficiency is 0 due to the alpha $(\alpha)$ term.

\subsection{The Model}

As described in previous sections, the primary objective of this paper is to test the effect leverage has on profit inefficiency in Australian banks.

ECAP (equity/assets) is used as the proxy of reversed leverage meaning a high ECAP illustrates low leverage and hence a low ECAP illustrates high leverage. Therefore the expectation according to agency theory and past literature (Berger and Bonaccorsi di Patti 2006) is that ECAP will have negative relationship with profit efficiency; that is an increase in debt yields higher profit efficiency. The model for the primary hypothesis:

$$
P E F F=f\left(E C A P+X_{i}\right)+e_{i}
$$

where $X_{i}$ denotes the control variables also believed to affect profit efficiency (PEFF).

Further findings we are hoping to unearth include determining whether agency theory variables other than leverage have any significant effect on profit efficiency. In our model we have included two such variables to proxy ownership structure, SH5OWN and SHINSIDE have been explained in section 4.2 along with their expected relationships with profit efficiency. Along with ownership structure, risk (SDROE), size of the bank (using assets as proxy) and market-share will all be regressed against profit efficiency.

As an alternative measure of bank performance a commonly used accounting measure is employed. The return on equity (ROE) is regularly used as a measure of firm performance and although it does not capture efficiency as such it does offer us a raw measure of bank performance. It therefore allows us to infer whether the explanatory variables affect firm 
performance in the same way as profit efficiency.

The model is specified as:

$$
R O E=f\left(E C A P+X_{i}\right)+e_{i}
$$

where $X_{i}$ denotes the control variables believed to affect the return on equity (ROE).

Berger and Bonaccorsi di Patti (2006) had a relatively large sample size, this enabled them to use the two-stage least squared method (2SLS) when modelling leverage on profit efficiency and vice versa. The (2SLS) is the preferred choice for models where reverse causality may possibly be in existence. Due to the restriction of our sample size some concessions had to made, one of those being that using the two stage least squares method was not usable. Instead a simple least squares method (LS) is utilized. Even though the method of regressing the variables differs to that of Berger and Bonaccorsi di Patti (2006), the results of this papers conclusions should not be seen as any less significant, the two stage least squares method simply has slightly more accurate assumptions.

\subsection{Reverse Causality}

It is not unimaginable that it is actually profit efficiency which drives the capital structure choice of a bank rather than capital structure driving profit efficiency, hence this paper tests for reverse causality using the Granger-causality test. The Granger-causality test was pioneered by Sims (1980) and it is conducted within a vector autoregressive (VAR) context, the test determines the order of information being processed between two variables. It is therefore important to note that a test finding variable $\mathrm{X}$ to Granger-cause variable $\mathrm{Y}$ does not automatically imply that $\mathrm{Y}$ is the direct result of $\mathrm{X}$ occurring, however the implications of information order can be just as important. They allow us to state whether past information of $\mathrm{X}$ predicts the value of $\mathrm{Y}$ or vice versa. It is best to employ as many lags as possible since fundamentally the Granger-causality test is based on determining the order of past information and its prediction power on the corresponding variable. Given our sample data, the Granger-causality test is implemented using the maximum lags available to us (2).

The general notation of a Granger-causality test which is trying to determine whether the lagged terms of X predict $\mathrm{Y}$ and whether the lagged terms of $\mathrm{Y}$ predict $\mathrm{X}$ respectively are specified as: ${ }^{1}$

$$
\begin{aligned}
& Y_{t}=\alpha_{0}+\alpha_{1} Y_{t-1}+\alpha_{2} Y_{t-2}+\ldots+\alpha_{p} Y_{t-p}+\beta_{1} X_{t-1}+\ldots+\beta_{p} X_{t-p}+\varepsilon_{t} \\
& X_{t}=\varphi_{0}+\varphi_{1} X_{t-1}+\varphi_{2} X_{t-2}+\ldots+\varphi_{p} X_{t-p}+\phi_{1} Y_{t-1}+\ldots+\phi_{p} Y_{t-p}+u_{t}
\end{aligned}
$$

where $\mathrm{p}$ is the number of lags, $\varepsilon_{t}$ and $u_{t}$ are the error terms. Equation 8 tests whether $\mathrm{X}$ Granger-causes $Y$, if beta $(\beta)$ does not equal to 0 significantly, we can say that $X$ is useful in forecasting Y. Equation 9 tests, whether it is $\mathrm{Y}$ that Granger-causes $\mathrm{X}$, if $\phi_{p}$ does not equal to 0 significantly we can say that $\mathrm{Y}$ Granger-causes $\mathrm{X}$.

There are two leading theories which suggest that profit efficiency may actually be causing capital structure, therefore it is imperative for us to test whether Australian banks do indeed show this to be true.

\footnotetext{
${ }^{1}$ We run two Granger causality tests. In the first we denote profit efficiency (PEFF) as Y and capital structure (ECAP) is X, in the second Granger-causality test we denote PEFF as $\mathrm{Y}$ and the quadratic variable of capital structure $(1 / 2 \mathrm{ECAP} 2)$ as $\mathrm{X}$.
} 
The efficiency-risk hypothesis expresses the idea; relatively efficient firms choose a capital structure which employs a relatively large proportion of debt as the added efficiency makes up for the added financial distress of having lower equity proportions.

The franchise-value hypothesis expects highly efficient firms to behave in an opposite manner. It argues, firms with relatively high efficiency are likely to maintain a high proportion of equity as said firm wants to protect its expected returns.

\section{Data and Variables}

The data originally consisted of a total 23 banks and financial institutions. 22 of those carry out their primary operations in Australia while 1 in New Zealand, this was 1 of the 7 banks and financial institutions dropped in the process of developing the model. The reasons some banks and financial institutions were dropped ranged from them being incomplete in their data availability to their operations not being active in the year of the sample date. The sample period begins in 2005 and concludes in 2007, this three year period was particularly chosen as it coincides with stable economic and financial market conditions and although it is relatively recent data, the time is distant enough from the recent "Global Financial Crisis". The most pronounced problem with incorporating the most recent data which coincides with the GFC would have been skewed figures of input costs and profit figures. The implications of this occurrence could have meant that the fair representation of banks characteristics studied was compromised.

The firm specific data was extracted from the OSIRIS database, in the case that data was not available in the OSIRIS database the official financial statements were revised and the appropriate data was obtained from there. In regards to the market variable of MARKETSHARE which represents the market-share of each bank, it was important that information was gathered from a reliable source hence, the source was the Australian Prudential Regulatory Authority (APRA).

\subsection{The Dependent Variables}

The primary variable which we are trying to explain with our model is the profit efficiency measure denoted as (PEFF). The problem of how to define efficiency in general regardless of its application is always a difficult one. In the case of this paper our concern is profit efficiency. A bank has several inputs that it uses to produce outputs hence in the case of banks, profit efficiency is the measure of outputs produced relative to a given amount of inputs. Profit efficiency increases with a relative increase of outputs given any amount of inputs. Maudos, Pastor, Perez, Quesada (2000) employ three inputs and three outputs in their quest to derive a profit efficiency measure, our paper uses this methodology as a base. We use very similar identifications of inputs and outputs however we have chosen to reduce the outputs to two rather than three. The reasoning being, there is no evidence to suggest that having three rather than two output definitions yields any gains or would bring about differing results hence using two outputs simplifies the profit efficiency specification slightly. Furthermore the format of information available in the OSIRIS database lent its self best to using two outputs.

The definitions of the inputs and outputs of our profit efficiency specification can be viewed below (summaries of all variables can be found in Table 1):

\section{Inputs}

There are three factor costs of production. 
$\mathrm{C} 1$ = the cost of loaned funds. This is defined as the interest expense divided by the corresponding amount owing. The amount owing is computed by adding up the liabilities of deposits and owing to other banks.

$\mathrm{C} 2=$ the cost of labour. The cost of labour is defined as the total amount spent on personnel divided by the total number of employees at the bank.

$\mathrm{C} 3=$ the cost of fixed assets. The cost of fixed assets is defined as the cost on plant and equipment divided by total fixed assets.

\section{Outputs}

There are two measures of yields from using the factors of production

$\mathrm{X} 1=$ Revenue from loans. As described in the title, output X1 is the net interest revenue from loans (in absolute values).

$\mathrm{X} 2=$ Revenue from other activities. As the title explains output X2 constitutes the net operating income from activities other than interest revenue.

Control variables include a profit, asset and equity variable. These are designed for the function to identify actual profit efficiency differences based on relative size of outputs given inputs rather than skewing figures due to differing values of the respective control variable.

It is important to draw comparisons of the primary regression which is run using the comprehensive profit efficiency measure to the results of using a more conventional accounting measure of performance. This allows us to test for whether the model is robust and can be extended to draw conclusions on whether the explanatory variables affect general firm performance as measured by the conventional accounting measure (ROE) in the same manner as they affect profit efficiency (PEFF).

The return on equity (ROE) is chosen to represent this comparative measure due to its popular application in finance and accounting, it provides a general measure of firm performance rather than an efficiency based measure, this gives a good foundation to draw comparisons and conclusions from. The specification for the measure of return on equity (ROE) is:

$$
R O E=\text { NET INCOME AFTER TAX / SHAREHOLDER'S EQUITY }
$$

It is quite likely that the explanatory variables will have very similar individual effects on both return on equity (ROE) and the profit efficiency measure (PEFF), however there are sure to be interesting finds in the process of comparing the two.

\subsection{The Explanatory Variables}

As mentioned in previous sections the common understanding in past papers is that along with the choice of capital structure, the ownership structure is also believed to have a significant impact on agency cost and therefore also profit efficiency (Jensen 1986) (Ang, Cole and Lin 2000).

The independent variable that captures capital structure which is used in our primary regressions is the ratio of equity divided by capital (ECAP). A low ECAP describes a bank with relatively high leverage while a high ECAP describes a bank with relatively low leverage. As was mentioned in previous sections the agency cost hypothesis suggests that profit efficiency and $E C A P$ have an inverse relationship $(\varphi \mathrm{ECAP} / \varphi \mathrm{EFF})>0$, the theory behind 
it suggests that a high ECAP or in other words low levels of leverage lead to managers having less incentive to work hard on maximizing potential profit as there is less financial distress on the bank. It is however important to also note that the expected relationship of the ECAP and profit efficiency can change if ECAP becomes small enough or in other words leverage has become high enough. In this case the financial distress caused by a marginal increase of leverage outweighs the agency cost benefits and therefore can produces a scenario where $(\varphi \mathrm{ECAP} / \varphi \mathrm{EFF})>0$.

The most obvious solution to this problem is to run an alternative regression which employs a quadratic variable of ECAP to test whether leverage does affect profit efficiency by varying amounts at different levels of debt. Therefore in the second regression of our primary objective the term $1 / 2 E C A P \wedge 2$ is added to test whether the relationship of capital structure and profit efficiency is a quadratic one.

As a means of testing for robustness of the results from the primary regressions the variable loans/assets (L/A) will be interchanged with ECAP, obviously these two variables are highly correlated and will therefore not be included in the same regression output. The variable $(L / A)$ measures the banks loans owing (deposits and amount owing to other banks) divided by the total assets. The interpretation is opposite to that of the ECAP, a high $L / A$ shows relatively high leverage while a low $L / A$ shows relatively low leverage.

While capital structure may be relatively easy to quantify, the same can not be said about ownership structure. The reason being that ownership structure is a topic which encompasses several subsections that are both quantitative and qualitative. In order to correctly specify a model for ownership structure several variables need to be created to accounting for these many subsections. In order to quantify ownership structure accurately, several variables were used. As was mentioned ownership structure inherently incorporates many quantitative and qualitative variables, therefore allowing for multiple variables in the model to estimate allows a more concise conclusion of the effects ownership structure has on profit efficiency.

The variable SHINSIDE measures the percentage of ownership directly held by board members (also including family members) as measured by stock. It is generally considered to be a positive signal to the market for board members to have shareholdings in their respective firms; such actions demonstrate an expectation of future growth of the firm. Exploring the idea of agency theory also ignites the idea of SHINSIDE being positively correlated with profit efficiency. Fundamentally agency theory is the conflict of interest between shareholders and decision makers of firms (managers, board members etc.), therefore colluding the two interests by making the decision makers shareholders should drive decision makers to find solutions in the best interest of shareholders. SH5OWN depicts the proportion of ownership held in blocks greater than $5 \%$ by individual share holders. It is expected that banks with relatively large values of $S H 5 O W N$ are going to have relatively lower inefficiencies as these are mitigated by having influential shareholders watching over the performance of the decision makers.

A variable is introduced to account for dissimilarities in bank performance which are attributed to size differences. Total assets are used as a proxy of size as it achieves the most accurate description of size. It is common practice to employ several dummy variables, however considering the small nature of the sample in this paper only 1 dummy variable is used. The data is split into two categories, the larger half of banks according to asset size are given the value of 1 while the smaller half of banks were given a value of 0 .

Risk is another bank characteristic which is generally believed to influence profit efficiency. 
It would not be wrong to assume that variables such as (L/A) and (ECAP) already form some sort of measurement of risk, these variables measure leverage which in itself is a component of overall risk. Therefore the risk these variables account for may not be complete, it is important to have a unique variable which explicitly measures risk. This variable is (SDROE) and it measures the standard deviation of the return on equity. Empirically it would be expected that the level of risk is positively correlated with profit efficiency, agency theory suggests higher risk encourages a stronger work ethic, hence profit efficiency is increased. To determine the standard deviation of return on equity (ROE), actual observations of (ROE) were made over 4 consecutive years for each bank, hence the standard deviation was found employing a general definition of standard deviation. SDROE is defined as:

$$
\sigma=\sqrt{\frac{1}{N} \sum_{i=1}^{N}\left(x_{i}-\mu\right)^{2}}
$$

where $(\sigma)$ is defined as the standard deviation of ROE, $(N)$ is the number of observation, $x i$ is the individual observation and $\mu$ defined as the mean of the 4 year observations for each individual bank.

A variable to control market share also constitutes part of the model (MKTSH), although total assets may give a good indication of market share it is not the preferred measure of previous studies, this is understandable as total assets do not directly equal to a one-to-one relationship with market share, instead a more conventional measure using total deposits of market share is used. The data of individual banks total deposits as well as the total deposits in the market were retrieved from the Australian Prudential Regulation Authority (APRA). The top 10 banks had a total market share of around 75 percent, the reasonable assumption was that the rest of the banks in the sample had equal share of the remaining 25 percent. The efficiency structure hypothesis states that it is actually efficiency of firms which determines market share; however this paper attempts to find whether there is a relationship that works in the other direction, that is we test if market share has a positive or indeed negative influence on profit efficiency.

\section{Results}

\subsection{Descriptive Statistics}

Here the properties of our profit efficiency findings are discussed. It is essential to our paper to have reliable and robust profit efficiency results of banks in Australia.

Table 1 depicts a very interesting picture and signify the importance of this paper. The results reflect the profit efficiency figures of Australian banks as specified by the purposely developed profit efficiency equation (Equation 5). It shows profit efficiency in Australian banks to be averaging $78.6 \%$; that is, on average banks profit efficiency is $78.6 \%$ relative to the performance of the most profit efficient bank. It is important not to forget what the implications of profit efficiency are, profit efficiency measures the actual output produced given any level of inputs required to create said outputs. The percentage of relative profit efficiency is then based on the most efficient bank and its ability to produce outputs given the level of inputs. Remembering this, it is then clear that the importance of the figures is not the mean $78.6 \%$ profit efficiency but rather the consequential mean profit inefficiency of $21.4 \%$. This figure implies on average, banks can increase profit by $21.4 \%$ by simply adjusting behaviour to be in line with that of the best practice bank. It is the duty of management to achieve maximum possible profit efficiency hence any action which a bank is able to take to 


\section{Macrothink}

Asian Journal of Finance \& Accounting

ISSN 1946-052X 2012, Vol. 4, No. 1

increase incentives for managerial staff to improve performance could yield large increases in profits.

Table 1. Summary Table of all Variables

\begin{tabular}{|c|c|c|c|}
\hline Variable & Explanation & Mean & Std. Dev. \\
\hline \multicolumn{4}{|c|}{ Endogeneous variable } \\
\hline PEFF & Profit efficiency measure & .7861 & .2678 \\
\hline ROE & Accounting measure of Return on Equity & .1577 & .0513 \\
\hline \multicolumn{4}{|c|}{ Explanatory variables } \\
\hline $\mathrm{L} / \mathrm{A}$ & Loans (deposits, owing to other banks)/ Total Assets & .8315 & .1256 \\
\hline ECAP & Total Financial Equity/Total Assets & .0633 & .0407 \\
\hline SHINSIDE & $\%$ of direct share ownership by directors and their families & .0366 & .0497 \\
\hline SH5OWN & $\%$ of shares held by shareholders with total holdings of over $5 \%$ & .2409 & .1819 \\
\hline SIZE & Total Assets & 128348575 & 165888162 \\
\hline MARKETSHARE & $\%$ share of depoits held by bank relative to overall market & .064957 & .065098 \\
\hline SDROE & Standard deviation of Return on Equity & .0310 & .0174 \\
\hline $1 / 2 \mathrm{ECAP}^{\wedge} 2$ & & .0028 & .0046 \\
\hline \multicolumn{4}{|l|}{ Determinants of } \\
\hline \multicolumn{4}{|l|}{ Profit Efficiency } \\
\hline $\mathrm{X} 1$ & Net Revenue from Loans (Interest) & 2142224 & 2988490 \\
\hline $\mathrm{X} 2$ & Net Revenue from other than loans & 1708502 & 2018601 \\
\hline $\mathrm{C} 1$ & Cost of Funds & .0717 & .0590 \\
\hline $\mathrm{C} 2$ & Cost of Labour & 92.335 & 51.300 \\
\hline $\mathrm{C} 3$ & Cost of Fixed Assets & .3081 & .2139 \\
\hline $\mathrm{P}$ & Profit & 1813716 & 2433989 \\
\hline $\mathrm{P} / \mathrm{A}$ & Profit/Total Assets & .0130 & .0046 \\
\hline $\mathrm{E}$ & Equity & 6918591 & 8677036 \\
\hline A & Total Assets & 128348575 & 165888162 \\
\hline
\end{tabular}

The standard deviation of .2678 or $26.78 \%$ shows a relatively profound difference in profit efficiency across banks. Once again due to the limitations on sample size availability these standard deviation figures may be slightly distorted due to a few outliers. The effect of these outliers however, must not be overstated as the efficiency results should still be deemed stable and reliable.

Skewness of -1.96 is in accordance with our intuitive expectation of what it should be for our data. The negative sign shows that most of the observations of profit efficiency lie close to 1 however there are a very few extreme outliers closer to 0 , this fits in with how we expect profit efficiency to behave. One would expect profit efficiency of banks to be in the higher end of the spectrum relative to the best practice bank however, due to how efficiency is calculated there is bound to be very few extreme figures close to 0. Graphically the expected skewness of profit efficiency can be represented by Figure 1. 


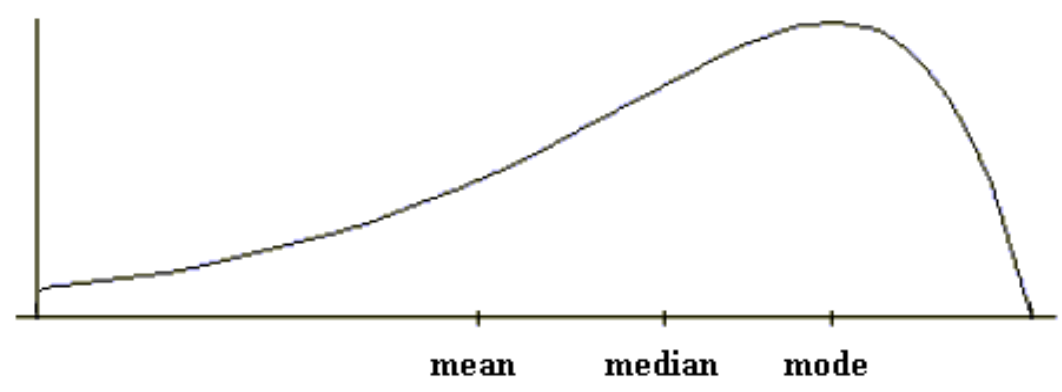

Figure 1. General representation of negative skewness

The kurtosis figure of 5.69 is a relatively high value, once again this coincides with the observed descriptive statistics before it. A figure of 5.69 suggests that a large proportion of the standard deviation in profit efficiency is brought on by extreme values. This once again can be explained by the nature of the measure of profit efficiency, a few extreme values are to be expected.

\subsection{The Effect of Explanatory Variables on Profit Efficiency (PEFF)}

Table 2 displays the significance and the magnitude of the relationship between the explanatory variables and the dependant variables of the differing models. As explained in previous sections all models were regressed using the least squares method. The variables are listed with their coefficients and their corresponding standard errors listed right below the coefficient figures.

The two primary regressions are run in order to determine the nature of leverage on profit efficiency, that is to distinguish whether the relationship of leverage on profit efficiency is linear or quadratic. The four following regressions are forms of robustness tests. The first specification tests the whether there is indeed a linear relationship of leverage as measured by equity/assets (ECAP) on profit efficiency. Though the sign is negative meaning increased leverage leads to increased profit efficiency which is as we would expect given agency theory, the result is statistically insignificant at any significance level.

Further analysis of this regression reveals the variables SHINSIDE (director share ownership) and SDROE (risk) to carry a positive relationship with profit efficiency though once again being statistically insignificant. The signs of both of these variables are as expected, we discussed the expected effect of risk and director share ownership on profit efficiency, both were expected to increase management's efficiency. The variable for size (SIZEDUMMY) shows negative yet statistically insignificant correlation with profit efficiency. SH5OWN has significant negative sign, this goes against the experiences of previous papers as well as theory. Empirically it is believed that large block ownership acts as an unofficial governing body however, our result would suggest the opposite to be true; large block ownership may act as a hindrance. MARKETSHARE is significant at the 5\% significance level and is positively correlated with profit efficiency, that is increased market share increases profit efficiency. The adjusted $\mathrm{R}^{\wedge} 2$ value shows that about $28 \%$ of variation in profit efficiency is explained by the explanatory variables. 
Table 2. Regression output

\begin{tabular}{|c|c|c|c|c|c|c|}
\hline Dependant variable & PEFF & PEFF & PEFF & PEFF & ROE & ROE \\
\hline \multirow[t]{2}{*}{ Constant } & $.833 * * *$ & $1.223 * * *$ & $.766 * *$ & 1.162 & $0.164 * * *$ & -.489 \\
\hline & 0.124 & 0.174 & 0.291 & 1.914 & 0.033 & 0.335 \\
\hline \multirow[t]{2}{*}{ ECAP } & -1.039 & $-14.166 * * *$ & & & $-2.525 * * *$ & \\
\hline & 1.098 & 4.559 & & & 0.861 & \\
\hline \multirow[t]{2}{*}{$(1 / 2) \mathrm{ECAP}^{\wedge} 2$} & & $119.93 * * *$ & & & $24.568 * * *$ & \\
\hline & & 40.635 & & & 7.677 & \\
\hline \multirow[t]{2}{*}{ L/A } & & & 0.082 & -1.106 & & $1.864^{*}$ \\
\hline & & & 0.34 & 5.68 & & 0.995 \\
\hline \multirow[t]{2}{*}{$(1 / 2) L / A^{\wedge} 2$} & & & & 1.59 & & $-2.641^{*}$ \\
\hline & & & & 7.587 & & 1.329 \\
\hline \multirow[t]{2}{*}{ SH5OWN } & $-0.0543^{*}$ & $-0.821 * *$ & $-.602 * *$ & $-0.576^{*}$ & 0.045 & 0.033 \\
\hline & 0.279 & 0.272 & 0.292 & 0.322 & 0.051 & 0.056 \\
\hline \multirow[t]{2}{*}{ SHINSIDE } & 1.709 & 2.718 & 1.302 & 1.405 & 0.326 & 0.13 \\
\hline & 1.112 & 1.07 & 1.152 & 1.267 & 0.202 & 0.222 \\
\hline \multirow[t]{2}{*}{ SDROE } & 1.581 & 1.996 & 0.363 & 0.686 & 0.699 & 0.385 \\
\hline & 2.644 & 2.415 & 2.43 & 2.901 & 0.456 & 0.508 \\
\hline \multirow[t]{2}{*}{ SIZEDUMMY } & -.139 & 0.055 & -0.122 & 0.113 & 0.027 & -.030 \\
\hline & 0.121 & 0.128 & 0.121 & 0.13 & 0.024 & 0.023 \\
\hline \multirow[t]{2}{*}{ MARKETSHARE } & $1.687 * *$ & $2.013 * * *$ & $1.544 *$ & $1.622 *$ & $0.401 * * *$ & $319 *$ \\
\hline & 0.744 & 0.688 & 0.814 & 0.904 & 0.13 & 0.158 \\
\hline F-Value & 3.846 & 5.209 & 3.626 & 3.036 & 5.518 & 4.673 \\
\hline Prob(F-stat) & 0.004 & 0.0003 & 0.006 & 0.0126 & 0.0002 & 0.0008 \\
\hline Adj. $\mathrm{R}^{\wedge} \mathbf{2}$ value & 0.28 & 0.401 & 0.264 & 0.245 & 0.418 & 0.369 \\
\hline \multicolumn{7}{|c|}{$\neq * *$ denotes significance at the $1 \%$ significance level } \\
\hline \multicolumn{7}{|c|}{ ** denotest aignificance at the $5 \%$ significance level } \\
\hline \multicolumn{3}{|c|}{ * denotes significance at the $10 \%$ significance level } & & & & \\
\hline
\end{tabular}

The second column consists of the regression which attempts to model a quadratic relationship between capital structure and profit efficiency hence the variable $1 / 2 \mathrm{ECAP}^{2}$ is added. The variable $1 / 2 \mathrm{ECAP}^{2}$ is a quadratic term of capital structure. The model yields an almost surprising increase in overall explanatory power as well as significance of ECAP on profit efficiency. The adjusted $\mathrm{R}^{2}$ value has increased by around $12 \%$ to a total of $40.1 \%$. More importantly the indication given by the model regarding leverage is that there is a statistically significant relationship of leverage on profit efficiency. As ECAP is implicitly the inverse of leverage we must intuitively recognise the relationship of leverage and profit efficiency is as theory would suggest. The regression output shows at low levels of leverage (high levels of ECAP) a marginal increase in debt increases the profit efficiency of banks in Australia. At relatively high levels of leverage (low levels of ECAP) a marginal increase in debt actually decreases the profit efficiency of banks. Theory would suggest that this is due to the increased financial distress caused by already high debt levels.

Ceteris paribus the derivative of: $f(P E F F)=1 / 2 E C A P \wedge 2+E C A P+C$ in the model is $f^{\prime}(P E F F)=119.93-14.166 E C A P$ which illustrates that the behaviour of leverage on profit efficiency is according to that of the major theories presented in this paper. Along with leverage now being statistically significant in explaining profit efficiency at any significance level, SH5OWN and MARKETSHARE remain statistically significant at the 5\% significance level and $1 \%$ significance level respectively while offering the same directional relationship as in the initial regression. SHINSIDE, SDROE and SIZEDUMMY are all still statistically insignificant as they were in the initial regression. In the process of determining variables to 
use in the model, both SHINSIDE and SDROE had shown quadratic relationships with profit efficiency in the paper of Berger and Bonaccorsi di Patti (2006). Therefore we tested whether quadratic relationships were in existence for either variable and both yielded unsatisfactory results. They also did not add to the overall explanatory power of the model and in fact reduced it, hence neither variable was included in the regression outputs.

\subsection{Robustness Checks}

Three methods are used to check for robustness of our results. Firstly to test whether it remains that the relationship of leverage and profit efficiency in Australian banks is a quadratic rather than a linear one, an alternate measure of leverage is used. $L / A$ as used by Muados, Pastor, Perez, Quaseda (2000), measures Loans/Assets (loans are made of deposits and other short term funding as well as other funding). The results of this regression suggest that there is no statistically significant relationship of leverage and profit efficiency whether it be linear or quadratic. The answer to this puzzling outcome may lie in the proxy of leverage $L / A$ as it may not encapsulate the total amount of leverage taken on by a firm. Debt may come from other places other than deposits and other loans, hence $L / A$ may just not be a great proxy of leverage. This notion is also strengthened when comparing the overall strength of the model which employs the quadratic form of ECAP to that which uses the quadratic form of L/A, you find that the model using L/A as a proxy of leverage has much lower explanatory power. The findings of this robustness test also strengthen the idea that banks should try to increase market share as well as reduce block ownership over $5 \%$, as both of these remain statistically significant.

Since the first robustness check did not give clarity on the issue of whether the model is robust a second robustness test is initiated. This robustness test as used by Berger and Bonaccorsi di Patti (2006) employs the common accounting measure of firm performance ROE (return on equity) as the dependant variable as an alternative to profit efficiency. The findings are of this robustness check is favourable to our primary model, when ECAP is used to proxy inverse leverage the findings are robust even when using a common accounting measure of firm performance (ROE). The findings of this robustness test are that leverage affects bank performance in a quadratic manner rather than a linear one. ECAP is statistically insignificant at any level when testing the linear relationship of ECAP and ROE (regression not shown here), however when the quadratic relationship of ECAP and ROE is examined it is statistically significant at any significance level.

Furthermore this robustness test finds market share to once again be positively correlated with bank performance with statistical significance. SH5OWN is significant at the $10 \%$ significance level when the regression is run with linear ECAP on ROE however it is insignificant at even the $10 \%$ level in the case of the quadratic relationship with ROE being specified. All other variables remain statistically insignificant at any level.

Finally a Granger-causality test is employed to test whether profit efficiency (PEFF) actually causes choice in capital structure (ECAP). This is indeed against the underlying assumption of our paper in which we model the impact of capital structure on profit efficiency. Both the efficiency-risk hypothesis and the franchise-value hypothesis offer considerable arguments as to why causality may be in the direction of profit efficiency to capital structure. The test is set up so that Granger-causality is tested between the linear terms of ECAP and PEFF as well as the quadratic term of ECAP (denoted ECAPSQ) and PEFF.

Table 3 shows that when the Granger-causality test is conducted with 2 lags between the linear term of ECAP and PEFF we find that Granger-causality does not run in either direction. 
This does compliment the findings of our primary regression which suggested that there is no relationship between capital structure and profit efficiency.

Table 3. Granger-causality test ${ }^{2}$

\begin{tabular}{llll}
\hline Null Hypothesis: & Obs & F-Statistic & Probability \\
\hline ECAP does not Granger Cause PEFF & 15 & 1.44382 & 0.28128 \\
PEFF does not Granger Cause ECAP & & 0.56267 & 0.58672 \\
\hline 1/2ECAP^2 does not Granger Cause PEFF & 15 & 3.06392 & $0.09165^{*}$ \\
PEFF does not Granger Cause 1/2ECAP^2 & & 0.44492 & 0.65297 \\
\hline
\end{tabular}

* denotes significance at the $10 \%$ level

The second set of output results confirm the findings of our paper that capital structure has a significant quadratic impact on profit efficiency and not the other way around. The output concludes that the quadratic term of capital structure $\left(1 / 2 \mathrm{ECAP}^{\wedge} 2\right)$ Granger-causes profit efficiency (PEFF) at the 10\% significance level and also importantly profit efficiency (PEFF) does not Granger-cause the quadratic term of capital structure $\left(1 / 2 \mathrm{ECAP}^{\wedge} 2\right)$ at any significance level. These results complement our primary findings and conclude that the causality of capital structure and profit efficiency runs in only one direction and that relationship is quadratic.

\section{Conclusion}

This paper sets out to contribute to the theory of capital structure in two major ways; the primary objective is to create a specific hypothesis for the effects capital structure has on firm performance in the financial sector, using the data of Australian 15 Australian ADIs over the period of 2005-2007. The secondary objective was to create a profit efficiency function that is profound yet simple enough to be employed on a dataset as limited as ours. These objectives have been accomplished successfully, we have shown a clear and robust relationship between capital structure and firm performance $\mathrm{s}$ well as created a profit efficiency function that works very well under any condition.

The main hypothesis: "How does capital structure affect firm performance of Authorised Deposit-taking Institutions (ADIs) using explicitly Australian data?" is one which is of especially great use for Australian banks but its implications could also extend to international data.

According to the theory of agency cost, higher levels of debt decrease the agency cost of the separation of ownership and management. This is driven by the increased financial distress caused by the higher debt levels. The added financial distress then forces management to work harder and act in the shareholders best interest. In contrast, at high levels of debt, the financial distress of proportionally increasing debt may outweigh any agency cost benefits received from such debt increases; hence this may have the effect of increasing the overall agency cost inherited by the Bank. Reverse causality could be argued with both the efficiency-risk and franchise-value hypotheses, offering plausible explanations of firm efficiency affecting capital structure choice; these are tested for. Berger and Bonaccorsi di Patti (2006) find support for the agency cost hypothesis; their findings show higher leverage

\footnotetext{
${ }^{2}$ All Granger-causality tests are run using 2 lags as this is the maximum plausible lags available to our dataset.
} 
to be associated with higher profit efficiency. Along with the use of the previously described profit efficiency measure, a common accounting performance measure is used to test for robustness as well as draw comparisons from the comparative measures.

Our findings show a significant and robust quadratic relationship between capital structure and firm performance of Australian ADIs. At relatively low levels of leverage an increase in debt leads to increased profit efficiency hence superior bank performance, at relatively high levels of leverage increased debt leads to decreased profit efficiency as well as bank performance. This can most likely be attributed to financial distress outweighing any gains made from managerial performance improving. The implications of this finding are considerable; we have found that a bank can help optimize the performance of management and general bank performance by simply choosing a capital structure which optimizes managerial incentives while keeping financial distress relatively low.

Further findings show that increased market share also leads to increased profit efficiency while the variable SH5OWN which describes ownership held in blocks greater than 5\% contradicts results of previous papers. Previous papers have shown increased block ownership acts as a governing body and therefore increases profit efficiency, however our results do not complement these findings. Our model also shows performance of Australian banks is not significantly affected by its size (SIZEDUMMY) or operating risk (SDROE).

The results of our primary hypothesis are robust even when replacing the variable ECAP (Equity/Total assets) with the variable L/A (Loans/Total assets) as well as when the dependant variable PEFF (profit efficiency measure) is replaced by a common accounting measure of firm performance ROE (return on equity). Furthermore the Granger-causality test discredits the idea that it is actually profit efficiency which drives capital structure as is suggested by certain past literature and instead it confirms that the capital structure is actually driving profit efficiency albeit quadratically.

\section{References}

Agrawal, A., \& Knoeber, C. R. (1996). Firm performance and mechanisms to control agency problems between managers and shareholders. The Journal of Financial and Quantitative Analysis, 31, 377-397. http://dx.doi.org/10.2307/2331397

Ang, J. S., Cole, R.A., \& Lin, J.A. (2000). Agency costs and ownership structure. The Journal of Finance, 1, 81-106. http://dx.doi.org/10.1111/0022-1082.00201

Barth, J. R., Caprio, G. Jr., \& Levine, R. (2004). Bank regulation and supervision: what works best? Journal of Financial Intermediation, 13, 205-248. http://dx.doi.org/10.1016/j.jfi.2003.06.002

Berger, A.N., \& Bonaccorsi, di Patti E. (2006). Capital structure and firm performance: A new approach to testing agency theory and an application to the banking industry. Journal of Banking \& Finance, 30, 1065-1102. http://dx.doi.org/10.1016/j.jbankfin.2005.05.015

Berger, A. N., \& Mester, L. J. (1997). Inside the black box: What explains the differences in the efficiencies of financial institutions? Journal of Banking \& Finance, 21, 895-947. http://dx.doi.org/10.1016/S0378-4266(97)00010-1

Cambello, M. (2003). Capital structure and product markets interactions: evidence from business cycles. Journal of Finance Economics, 68, 353-378. http://dx.doi.org/10.1016/S0304-405X(03)00070-9 
Carpentier, C. (2006). The valuation effects of long term changes in capital structure. International Journal of Managerial Finance, 2, 4-18. http://dx.doi.org/10.1108/17439130610646144

Eisenhardt, K.M. (1989). Agency theory: An assessment and review. The Academy of Management Review, 14, 57-74.

Fama, E.F., \& Jensen, M.C. (1983). Separation of ownership and control. Journal of Law and Economics, 26, 301-325. http://dx.doi.org/10.1086/467037

Grossman, S.J., \& Hart, O.D. (1982). Corporate financial structure and managerial incentives. In J. McCall (Ed.), The economics of information and uncertainty. Chicago: University of Chicago Press.

Harris, M., \& Raviv, A. (1991). The theory of capital structure. The Journal of Finance, 46, 297-355. http://dx.doi.org/10.2307/2328697

Jensen, M.C., \& Meckling, W.H. (1976). Theory of the firm: Managerial behaviour, agency costs and ownership structure. Journal of Financial Economics, 3, 305-360. http://dx.doi.org/10.1016/0304-405X(76)90026-X

Margaritis, D., \& Psillaki, M. (2007). Capital structure and firm efficiency. Journal of Business Finance \& Accounting, 34, 1447-1469.

Maudos, J., Pastor, J.M., Perez, F., \& Quaseda, J. (2002). Cost and profit efficiency in European banks. Journal of International Financial Markets, Institutions and Money, 12, 33-58. http://dx.doi.org/10.1016/S1042-4431(01)00051-8

Modigliani, F., \& Miller, M.H. (1958). The cost of capital, corporation finance and the theory of investment. The American Economic Review, 48, 261-297.

Myers, S.C. (1977). Determinants of corporate borrowing. Journal of Financial Economics, 5, 147-175. http://dx.doi.org/10.1016/0304-405X(77)90015-0

Myers, S. C. (1984). The capital structure puzzle. The Journal of Finance, 39, 575-592. http://dx.doi.org/10.2307/2327916

Myers, S.C., \& Majluf, N. (1984). Corporate financing and investment decisions when firms have information that investors do not have. Journal of Financial Economics, 13, 187-221. http://dx.doi.org/10.1016/0304-405X(84)90023-0

Opler, T.C., \& Titman, S. (1994). Financial Distress and Corporate Finance. The Journal of Finance, 49, 1015-1040. http://dx.doi.org/10.2307/2329214

Richardson, G., \& Lanis R. (2007). Determinants of variability in corporate effective tax rates and tax reform: Evidence from Australia. Journal of Accounting and Public Policy, 26, 689-704. http://dx.doi.org/10.1016/j.jaccpubpol.2007.10.003

Shulman, C.T., Thomas, D.W., Keith, S.F., \& Kennedy, D.B. (1996). Effects of tax integration and capital gains tax on corporate leverage. The National Tax Journal, 49, 31-54.

Shyam-Sunder, L., \& Myers, S.C. (1999). Testing static tradeoff against the pecking order models of capital structure. Journal of Financial Economics, 51, 219-244. http://dx.doi.org/10.1016/S0304-405X(98)00051-8

Sims, C.A. (1980). Macroeconomics and reality. Econometrica, 48(1), 1-48. 
http://dx.doi.org/10.2307/1912017

\section{Copyright Disclaimer}

Copyright reserved by the author(s).

This article is an open-access article distributed under the terms and conditions of the Creative Commons Attribution license (http://creativecommons.org/licenses/by/3.0/). 